Proceedings of the XXIII Conference on Applied Crystallography, Krynica Zdrój, Poland, September 20-24, 2015

\title{
Structure and Properties of NiTi Shape Memory Alloy after Cold Rolling in Martensitic State
}

\author{
P. Świec, M. Zubko*, Z. LeKston And D. Stróż \\ Institute of Materials Science, University of Silesia, Chorzów, Poland
}

\begin{abstract}
Due to unique features, like shape memory effects and superelasticity, NiTi alloys with nearly equiatomic composition are used in various branches of industry. Application of severe plastic deformation can drastically change properties of the materials. In the present paper the $\mathrm{Ni}_{50.4} \mathrm{Ti}_{49.6}$ alloy after cold rolling in the martensitic state and further annealed is studied. Phase transformations were studied using X-ray diffraction and differential scanning calorimetry measurements. Microstructure was examined using transmission electron microscopy and electron backscattering diffraction methods. Mechanical properties of obtained alloys has been studied using Vickers microhardness tests. Based on the performed measurements it can be seen that in studied alloys two steps $B 2 \leftrightarrow R \leftrightarrow B 19^{\prime}$ phase transitions occurred. Performed plastic deformation influences course of phase transitions and phases composition. Due to the reduction of grain size microhardness of the studied material is increasing with increase of deformation degree.
\end{abstract}

DOI: 10.12693/APhysPolA.130.1081

PACS/topics: 81.30.Kf, 81.40.Ef, 62.20.fg

\section{Introduction}

NiTi alloys that exhibit one- and two-way shape memory effects and superelasticity, are classified as intelligent materials. Shape memory effects are related to reversible, thermoelastic martensitic transformation that occurs in these alloys upon cooling and heating, whereas superelasticity is associated with transformation induced by an external stress [1]. Due to the high content of titanium, these alloys are naturally self-passivating, which results in formation of thin film of titanium dioxide $\mathrm{TiO}_{2}$ known as rutile. This protects the material against corrosion. High mechanical properties, high corrosion resistance, and unique shape memory effects cause that the NiTi alloys are great materials for orthodontic arches, stents, staples for osteosynthesis or other implants and items used in medicine $[2,3]$.

Nanostructured NiTi shape memory alloys show better strength with high ductility. Nanostructure can be formed by severe plastic deformation which can also lead to material amorphization. The material is further annealed, to control grain growth and obtain the required microstructure with appropriate grain size $[4,5]$.

Examined alloy with nominal chemical composition $\mathrm{Ni}_{50.4} \mathrm{Ti}_{49.6}$ was produced by smelting and molding in vacuum induction furnace Balzers VSG 10 in Research and Development Laboratory for Aerospace Materials at Rzeszów University of Technology. Alloy after hot forging as rod with diameter of $3.5 \mathrm{~mm}$ was cold rolled in martensitic state on duo roller, cooling the material after each step in a bath of liquid nitrogen. The obtained rods with deformation of $5 \%, 15 \%, 20 \%$, and $30 \%$, were further annealed at $400^{\circ} \mathrm{C}, 450{ }^{\circ} \mathrm{C}$, and $500^{\circ} \mathrm{C}$. In order

\footnotetext{
*corresponding author; e-mail: maciej.zubko@us.edu.pl
}

to characterize the influence of applied plastic deformation and heat treatment on the alloy structure and properties the samples were examined by X-ray diffraction (XRD), differential scanning calorimetry (DSC), electron backscatter diffraction (EBSD) and transmission electron microscopy (TEM) crystallographic orientation mapping with precession electron diffraction (PED).

\section{Experimental}

An alloy of nominal chemical composition of $\mathrm{Ni}_{50.4} \mathrm{Ti}_{49.6}$ was produced by melting the alloying components in a Balzers VSG 10 vacuum induction furnace at the Research and Development Laboratory for Aerospace Materials Rzeszów University of Technology. The ingot was homogenised at $900^{\circ} \mathrm{C}$ and then it was hot forged to the final shape of a rod with $3.5 \mathrm{~mm}$ in diameter. Finally, the rod was cold rolled in the martensitic state on a duo rolling-mill. The material before each step of rolling was cooled in a bath of liquid nitrogen. Rods obtained in such treatment with deformation of $5 \%, 15 \%, 20 \%$, and $30 \%$, were further annealed at $400{ }^{\circ} \mathrm{C}, 450^{\circ} \mathrm{C}$, and $500^{\circ} \mathrm{C}$. The phase analysis of the obtained samples were performed by means of X-ray diffraction (XRD) on Philips PW 1130/00 diffractometer (working at $40 \mathrm{kV}, 30 \mathrm{~mA}, \lambda=1.54056 \AA$ ) in $20-110^{\circ} 2 \theta$ range. Determination of the characteristic temperatures of phase transformations was performed by differential scanning calorimetry (DSC) on Mettler Toledo DSC-1 during cooling and heating cycles with a temperature change rate of $10^{\circ} \mathrm{C} / \mathrm{min}$ at thermal range between $-100^{\circ} \mathrm{C}$ and $100^{\circ} \mathrm{C}$. EBSD measurements were performed on JEOL JSM-6480 Scanning Electron Microscope (working at $20 \mathrm{kV}$ ) for obtaining the orientation map of grain distribution for sample before cold rolling. Preparation of the samples for TEM was performed by polishing till gradation of $0.01 \mu \mathrm{m}$ and further electropolishing for 10 min using $6 \mathrm{~V} \mathrm{~cm}^{-1}$ on $\mathrm{H}_{4} \mathrm{SO}_{4}-\mathrm{MeOH}$ 1:5 electrolyte. Measurements of grains crystallographic 
orientation in samples after cold rolling was performed using PED method. For PED measurements JEOL 3010 transmission electron microscope (working at $300 \mathrm{kV}$ ) with $2 k \times 2 k$ Orius $^{\text {TM }} 833$ SC200D Gatan CCD camera was used. Electron diffraction patterns were recorded with $0.5^{\circ}$ precession angle using NanoMegas DigiStar electron beam precession attachment.

\section{Results}

Recorded DSC curves showed that initial material has the following characteristic temperatures: $M_{\mathrm{S}}=16.7^{\circ} \mathrm{C}$, $M_{\mathrm{f}}=4.2^{\circ} \mathrm{C}, A_{\mathrm{s}}=33.2^{\circ} \mathrm{C}$, and $A_{\mathrm{f}}=47.0^{\circ} \mathrm{C}$ (Fig. 1a). XRD measurements revealed presence of two phases in this material: martensite $B 19^{\prime}$ and parent phase $B 2$ (Fig. 1b). SEM observations using EBSD method showed that the average grain size is $15 \mu \mathrm{m}$ and this material does not show preferred orientation (Fig. 2). Microhardness of this material was $204 \mathrm{HV} 0.5$.
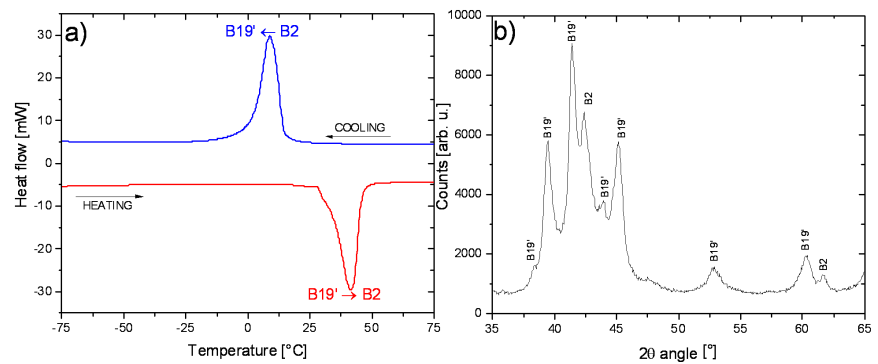

Fig. 1. (a) DSC curves and (b) XRD diffraction pattern for material without thermo-mechanical treatment.
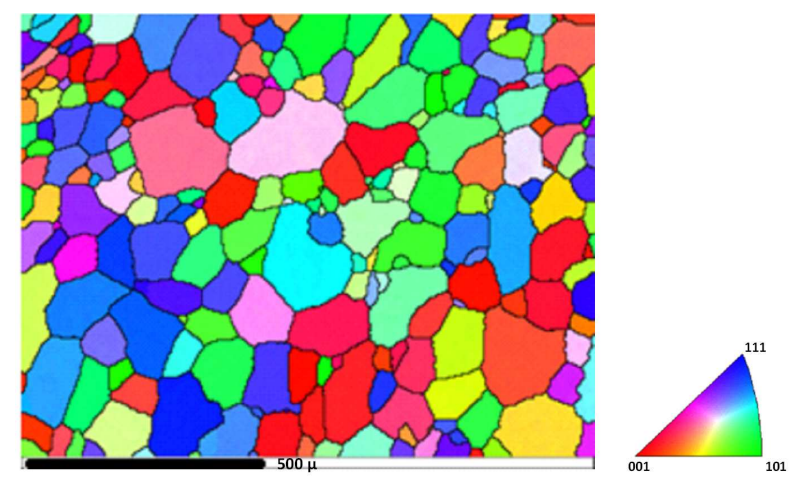

Fig. 2. Orientation map recorded for material without thermo-mechanical treatment obtained by EBSD measurements.

DSC curves for cold rolled material with different levels of deformation, annealed at $400^{\circ} \mathrm{C}$ for 15 min show three exothermic peaks during cooling. Temperature of thermal peaks corresponding to $R \rightarrow B 19^{\prime}$ phase transformation starts to decrease with increasing deformation degree. Their enthalpy is also decreasing and they are constantly getting blurred. Third peak $(B 2 \rightarrow R)$ starts to expand together with increasing deformation. DSC curves recorded during heating show one endothermic peak which spreads revealing two-stage inverse transformation (Fig. 3a). For samples with lower degree of deformation annealed at $450^{\circ} \mathrm{C}$ for $15 \mathrm{~min}$ one exothermic and one endothermic peaks are revealed corresponding to reversible phase transformation $B 2 \leftrightarrow B 19^{\prime}$. DSC curves for samples with higher deformation show two exothermic peaks whose enthalpy is increasing while enthalpy of $B 2 \rightarrow B 19^{\prime}$ peak is decreasing and they are getting blurred with increasing deformation degree. The endothermic peak spreads revealing two-stage inverse transformation (Fig. 3b). DSC measurement results for samples annealed at $500^{\circ} \mathrm{C}$ for 15 min show one exothermic peak corresponding to $B 2 \rightarrow B 19^{\prime}$ phase transformation but with increasing deformation degree it starts to spread to two-stage phase transformation. DSC curves show one endothermic peak corresponding to reverse phase transformation. At higher levels of deformation these peaks are blurred which suggests that reverse transformation occurs with the intermediate $R$ phase in small temperature range (Fig. 3c).
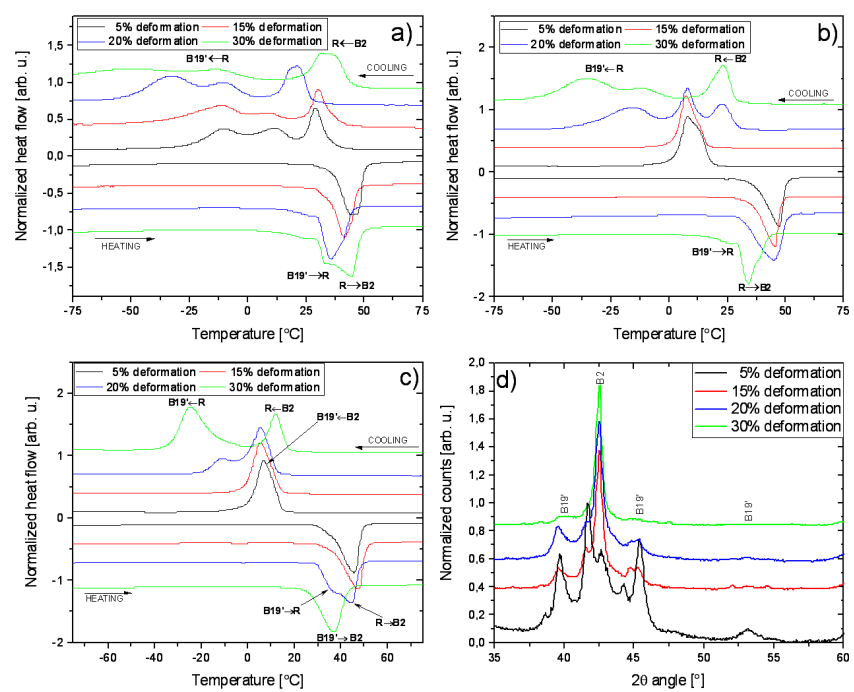

Fig. 3. DSC curves for sample annealed at (a) $400^{\circ} \mathrm{C}$, (b) $450{ }^{\circ} \mathrm{C}$, (c) $500{ }^{\circ} \mathrm{C}$ for $15 \mathrm{~min}$, (d) XRD pattern for sample annealed at $450^{\circ} \mathrm{C}$ for 15 min.

XRD patterns confirmed that 3 phases exist in the rolled material: $B 2$ (ICDD PDF 01-078-4616), $B 19^{\prime}$ (ICDD PDF 00-027-0344) and $R$ (ICDD PDF 01-076$7517)$. With increasing deformation degree peaks corresponding to the $B 19^{\prime}$ phase are fading and $B 2$ phase peaks intensity is growing. As excepted, FWHM of diffraction peaks is increased for samples with higher deformation (Fig. 3d).

Microhardness of sample annealed at $400^{\circ} \mathrm{C}$ for $15 \mathrm{~min}$ reached 296 HV0.5 after $5 \%$ cold rolling then starts to grow linearly reaching 330 HV0.5 after $30 \%$ cold rolling. Microhardness of sample annealed at $450{ }^{\circ} \mathrm{C}$ for $15 \mathrm{~min}$ starts to grow rapidly reaching $296 \mathrm{HV} 0.5$ after $5 \%$ deformation and after that it begins to slowly decrease linearly reaching 277 HV0.5 after $30 \%$ cold rolling. Sample annealed at $500{ }^{\circ} \mathrm{C}$ for 15 min show linear grow of microhardness reaching $254 \mathrm{HV} 0.5$ after $30 \%$ cold rolling (Fig. 4). 


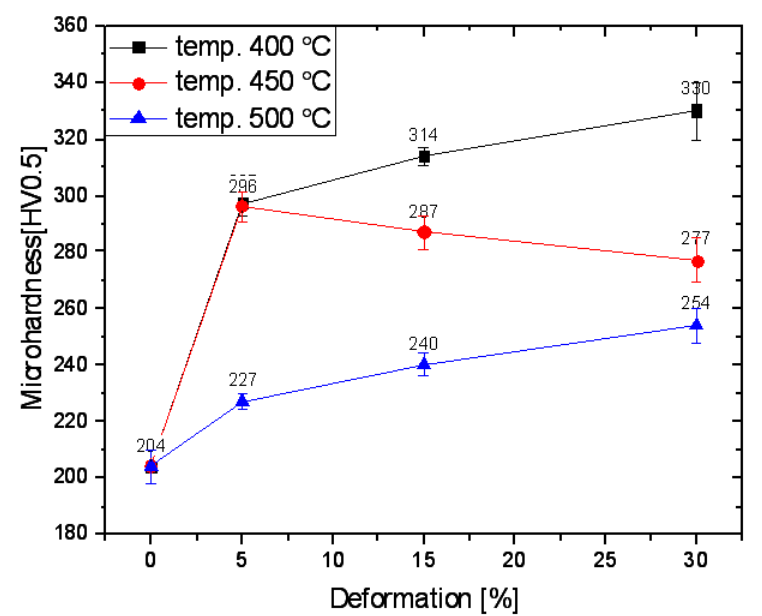

Fig. 4. Microhardness for sample annealed at $400{ }^{\circ} \mathrm{C}$, $450{ }^{\circ} \mathrm{C}$ and $500{ }^{\circ} \mathrm{C}$ for $15 \mathrm{~min}$.

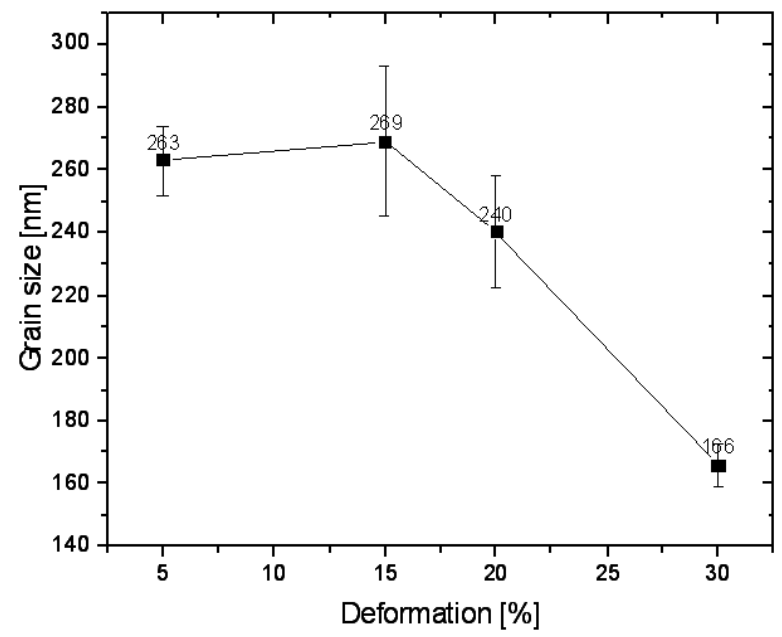

Fig. 5. Average grain size of $5 \%, 15 \%, 20 \%$ and $30 \%$ cold rolled material annealed at $500{ }^{\circ} \mathrm{C}$ for $15 \mathrm{~min}$.

Based on the TEM measurements it was determined that average grain size is decreasing with increase of deformation degree (Fig. 5). TEM images of 5\% cold rolled material annealed at $400^{\circ} \mathrm{C}$ for $15 \mathrm{~min}$ show big areas of martensitic plates $\left(B 19^{\prime}\right.$ phase) and it transformed to $B 2$ phase after further plastic deformation. Recovery process was observed in every samples annealed at $400^{\circ} \mathrm{C}$. Some part of the material was not fully recrystallized (Fig. 6). Fine grains were observed for $20 \%$ cold rolled material after annealing at $500^{\circ} \mathrm{C}$. Their size was in range 100-500 $\mathrm{nm}$ (Fig. 7). All observed samples had sphere-shape particles. Figure 8 shows crystallographic orientation map obtained after PED measurements for $20 \%$ cold rolled material annealed at $500^{\circ} \mathrm{C}$ for $15 \mathrm{~min}$. Grains do not exhibit preferred orientation but they are flattened in one direction (Fig. 8).

\section{Discussion}

After cold rolling and annealing material was tougher and more brittle. Phase transformation characteristic

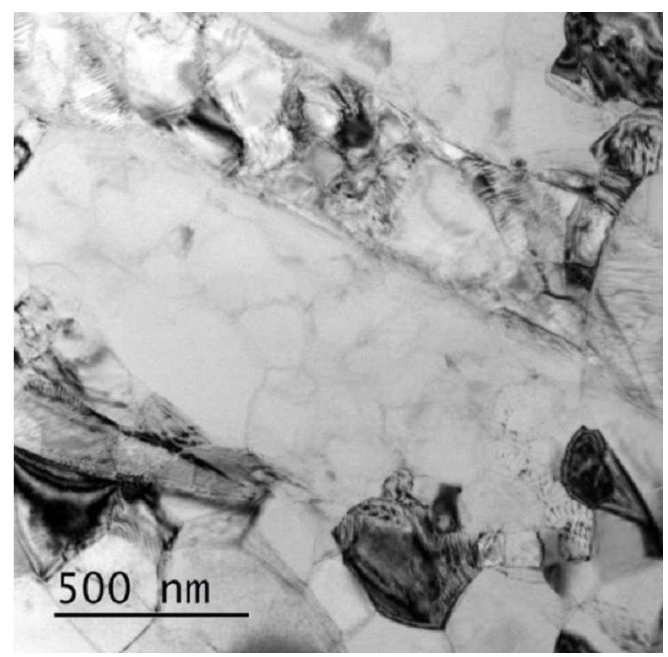

Fig. 6. TEM image of $5 \%$ cold rolled material annealed at $400^{\circ} \mathrm{C}$.

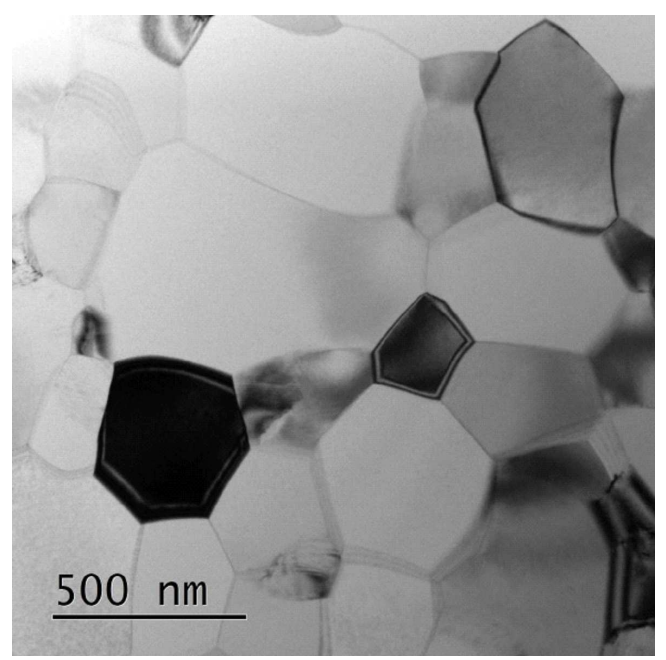

Fig. 7. TEM image of $20 \%$ cold rolled material annealed at $500{ }^{\circ} \mathrm{C}$ - fine grains of parental phase.

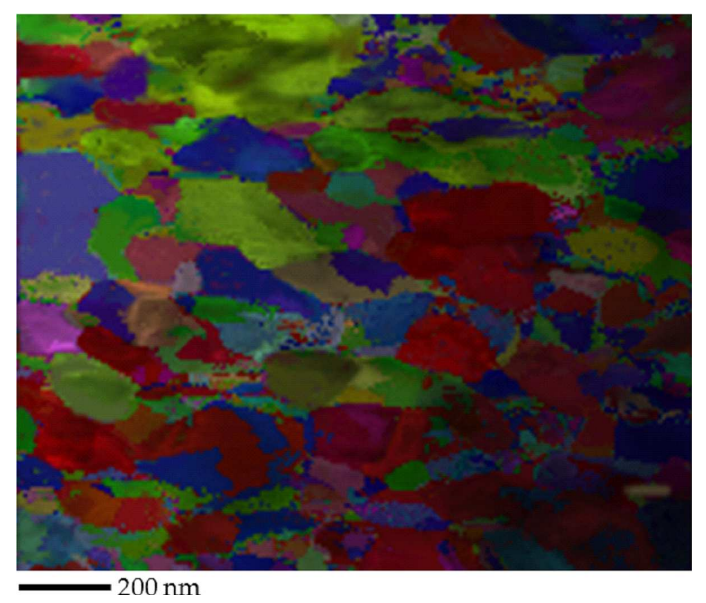

Fig. 8. Orientation map of $30 \%$ cold rolled material annealed at $500^{\circ} \mathrm{C}$ obtained using PED method. 
temperatures decreased with higher deformation degree and DSC peaks get blurred. It can be explained by stress implemented by deformation in the material structure. This stress caused appearance of $R$ phase and two-step martensitic transformation. Such behaviour is related to the influence of stress fields on the edges of dislocation walls which leads to increase in wall thickness. Greater wall thickness (which are phase separation boundaries during martensitic transformation) cause difficulties for martensitic transformation [6]. For 20\% cold rolled sample annealed at $450{ }^{\circ} \mathrm{C}$ three exothermic peaks were observed on DSC curves by which two of them correspond to $B 2 \rightarrow R \rightarrow B 19^{\prime}$ transformation and third to $B 2 \rightarrow B 19^{\prime}$ transformation. For $30 \%$ cold rolled sample, $B 2 \rightarrow B 19^{\prime}$ peak fades but $B 2 \rightarrow R$ and $R \rightarrow B 19^{\prime}$ peaks grow and two-stage martensitic transformation occurs.

On the basis of XRD measurements it was found that material after cold rolling contains 3 phases: parent $B 2$ phase, martensitic $B 19^{\prime}$ phase and intermediate $R$ phase. It can be seen that intensity of $B 2$ phase peaks increases and intensity of $B 19^{\prime}$ phase peaks decreases with growing deformation degree. It is caused by stress induced in the material by deformation which results in lowering characteristic temperatures. All peaks tend to increase their angular values with increasing deformation. On the XRD patterns for all samples broadening of diffraction peaks was observed with increased deformation degree. Such phenomena are related to the decrease of crystallites size which is also confirmed by TEM measurements. TEM images show that examined material with low deformation level possesses areas with martensitic plates. They are getting smaller when deformation and annealing temperature increases. Large and small grains were observed. That fact might indicate about coalescence process (recovery by grain growth with a small angle of disintegration). Polygonization process was observed in all samples. This process was on higher state in samples annealed in $500^{\circ} \mathrm{C}$. Grain refinement increases with increase of deformation and decrease of annealing temperature. It can be seen on sample annealed at $500{ }^{\circ} \mathrm{C}$. Smallest average grain size was $22 \mathrm{~nm}$ for $20 \%$ cold rolled material annealed at $450^{\circ} \mathrm{C}$. Grains were flattened which is typical for cold rolled materials.

\section{Conclusions}

1. After severe plastic deformation examined material still shows shape-memory effect.

2. Characteristic temperatures of the material decrease with increase of deformation degree and decrease of annealing temperature. This is directly related with stress induced in the material.

3. Examined NiTi alloy cold rolled in martensitic state annealed in low temperatures for short period of time occurs as two-step martensitic transformation.

4. Rhombohedral $R$ phase was induced by high stress fields. It occurs during cooling and heating.

5. Sample with the highest deformation and the lowest annealing temperature has the highest hardness. Sample with the lowest deformation and the highest annealing temperature has the lowest hardness.

\section{References}

[1] T. Duerig, D. Stoeckel, D. Johnson, Proc. SPIE 4763, 7 (2002).

[2] H. Morawiec, Z. Lekston, Medical implants with shape memory effect, (monograph), Wyd. Pol. Śl. w Gliwicach, Poland 2010 (in Polish).

[3] T. Yoneyama, S. Miyazaki, Shape memory alloys for biomedical applications, Woodhead Publ. Ltd and CRC Press LLC, England 2009.

[4] K. Otsuka, X. Ren, Progr. Mater. Sci. 50, 511 (2005).

[5] D. Stróż, J. Palka, Z. Lekston, G. Dercz, Mater. Sci. Forum 738-739, 501 (2013).

[6] H. Morawiec, J. Ilczuk, D. Stróż, T. Goryczka, D. Chrobak, J. Phys. IV 7, C5-155 (1997). 